\title{
Elección de gobernadores Regionales en Chile: \\ ESCENARIOS DE CAMBIO EN LAS RELACIONES \\ INTERGUBERNAMENTALES
}

\author{
Election of Regional Governors in Chile: Scenarios of Change in \\ Intergovernmental Relations.
}

\section{EGON MONTECINOS}

Universidad Austral de Chile

\begin{abstract}
RESUMEN
En este artículo se revisa la reforma política a la descentralización que comenzará a regir en plenitud a partir de las elecciones de gobernadores regionales de 2021. Basado en el enfoque de las relaciones intergubernamentales, se muestran posibles escenarios de falta de coordinación en la dinámica política regional que podrían desencadenar en conflictos a raíz de la existencia de dos nuevas autoridades regionales con similares atribuciones. Ante esta debilidad del nuevo diseño institucional, este artículo propone la creación de una instancia de coordinación de política regional. La principal conclusión es que la reforma de descentralización fue concebida más como un proceso de autonomía y democratización, que como una instancia de fortalecimiento de las relaciones intergubernamentales para implementar mejores políticas púbicas subnacionales.
\end{abstract}

Palabras clave: descentralización, democracia, gobernadores regionales, relaciones intergubernamentales, cooperación.

\begin{abstract}
This article reviews the political reform to decentralization in Chile that will begin to rule in full after the regional governors' elections of 2021. Based on an intergovernmental relations approach, I show possible scenarios of lack of coordination in regional political dynamics that could lead to conflicts as a result of the existence of two new regional authorities with similar powers. In view of the weakness of the new institutional design, this article proposes the creation of a regional policy coordination body. The main conclusion is that the decentralization reform was conceived more as a process of autonomy and democratization, than as an instance of strengthening intergovernmental relations in order to implement better subnational public policies.
\end{abstract}

Keywords: decentralization, democracy, regional governors, intergovernmental relations, cooperation. 


\section{INTRODUCCIÓN}

A partir del año 2021, Chile comenzará a vivir un proceso inédito de descentralización y democracia regional, dado que por primera vez en la historia republicana se elegirán autoridades de nivel intermedio. Este proceso de descentralización y democratización regional, aunque tardío, pondrá a Chile a la par de las democracias consolidadas y lo sacará del grupo de países dentro de la Organización para la Cooperación y el Desarrollo Económico (OCDE)que no eligen a sus autoridades regionales (hoy ese lugar lo comparte con Turquía).

Este sustantivo avance democrático, también modificará las relaciones intergubernamentales, y como consecuencia, alterará la dinámica política regional, poniendo más actores en la esfera decisional. No se tratará de una modificación de las relaciones intergubernamentales (en adelante RIGs) como habitualmente se ha dado en países unitarios descentralizados como, por ejemplo, Colombia o Perú. En ellos la autoridad electa es la principal autoridad política con presencia en la región, y con atribuciones de coordinación política de los servicios públicos regionales. En Chile se dará un caso excepcional, dado que se contará con dos nuevas autoridades regionales: una electa y otra designada.

Esto se produce a raíz de la principal reforma política aprobada en el año 2017 (ley 20.990), la cual consideró el reemplazo de la actual autoridad política regional (intendente regional) por dos nuevas autoridades. La primera de ellas será electa por la ciudadanía a partir del año 2021 y se llamará Gobernador Regional. La segunda autoridad será designada por el presidente de la república y se llamará Delegado Presidencial Regional. Ambas autoridades convivirán en la misma unidad administrativa (región) y gozarán de atribuciones y competencias similares para hacer gestión regional.

Sin duda, este inédito diseño producirá nuevas formas de RIGs y algunas "zonas grises" entre estas dos autoridades regionales, dado que compartirán ámbitos de acción, competencias y atribuciones, lo que hará compleja la relación entre ellas. Modificará la dinámica política regional que traerá ventajas indudables, como democratizar un espacio político, darle mayor estabilidad a la conducción política regional, pero también podría provocar ciertos inconvenientes, como dualidad de mando, o confusión en el liderazgo de la coordinación política regional. Producirá incentivos y efectos que alterarán las clásicas relaciones que se dan entre los niveles de gobierno central, regional y municipal. Por ejemplo, en la actualidad existe claridad política y ciudadana respecto de que el intendente regional es quien coordina a los servicios públicos a nivel regional. A partir del año 2021, y con la desaparición del intendente, las nuevas relaciones intergubernamentales serán entre municipalidades, gobernación regional, delegación presidencial regional y ministerios. Como consecuencia, las combinaciones posibles a partir de la incorporación de estos dos nuevos actores en la gestión regional, y la intensidad de las afinidades entre estos líderes políticos serán variadas y en distinta dirección. 
En este artículo se analizan las reformas políticas a la descentralización y se plantean posibles escenarios usando el enfoque teórico de las RIGs, respondiendo a la pregunta sobre ¿cuáles serán los principales problemas que se darán en las nuevas relaciones intergubernamentales en Chile? El artículo se estructura de la siguiente manera. En una primera parte se dan a conocer los principales elementos teóricos del enfoque de las relaciones intergubernamentales y la descentralización. Seguidamente se dan a conocer las principales reformas legales realizadas a la descentralización, poniendo especial énfasis en la ley de transferencia de competencias y en la de elección de gobernadores regionales. En una tercera parte se plantean algunos escenarios donde se podrían ver mayores alteraciones en las RIGs, cerrando esta sección con algunas propuestas políticas para reducir el impacto de esta posible problemática. Finalmente se cierra el artículo con algunas conclusiones.

\section{DESARROLLO}

\section{El enfoque de las relaciones intergubernamentales y la descentralización}

El desarrollo conceptual sobre descentralización que más consenso recibe en América Latina es el planteado por Tulia Falleti (2006), quien la define como "un proceso de reforma del Estado compuesto por un conjunto de políticas públicas que transfieren responsabilidades, recursos o autoridad de los niveles más altos de gobierno a los más bajos" (Falleti 2006: 320). La autora operacionaliza las tres dimensiones que implica el proceso, que son la fiscal, administrativa y política ${ }^{1}$, además de evidenciar la importancia de la secuencialidad en las reformas y el efecto e incentivos que provoca sobre actores nacionales y regionales.

A su vez, establece la necesaria relación que debe existir entre la transferencia de competencias, recursos, y autonomía política regional que implica la descentralización, con la debida unidad administrativa y coordinación entre los niveles de gobierno. Esta problemática le asigna un importante valor al debate sobre la autonomía subnacional y la unidad del Estado nacional que implican los procesos de descentralización. En términos generales, la cuestión central es cómo estos procesos responden a la necesidad de garantizar la unidad del Estado-nación con la autonomía política subnacional. Esto lleva a que las RIGs ofrezcan conceptos, hipótesis y modelos, que describen y explican la relación

Falleti señala que la descentralización administrativa es el proceso que implica "el conjunto de políticas que permiten transferir a los gobiernos subnacionales la administración y competencias de servicios sociales tales como educación, salud, asistencia social o vivienda", las que pueden ser acompañadas con recursos fiscales o no para su implementación. Por descentralización fiscal entiende el "conjunto de políticas destinadas a aumentar los ingresos o la autonomía fiscal de los gobiernos subnacionales (Falleti 2006: 321)." Por último, la descentralización política la operacionaliza como "el conjunto de reformas constitucionales y electorales destinadas a abrir nuevos espacios de representación subnacional, o a activar los que ya existían, pero permanecían latentes o inefectivos." 
entre autonomía y unidad, compatibilizando la autonomía de los niveles subnacionales con la unidad de la actividad administrativa. Lo anterior es abordado por Leyva Botero $(2011 ; 2012)$ quien analiza el caso de Colombia y señala que la descentralización no sólo implica una cuestión de autonomía, sino además de fortalecimiento de las relaciones intergubernamentales, donde es necesario observar la producción de éstas en cada unidad subnacional, en el marco general del proceso de descentralización (Leyva Botero 2012: 122). Esto lo ha llevado a concluir que, por ejemplo, la descentralización en Colombia no ha tenido los éxitos esperados, en parte porque el proceso no se consideró como una oportunidad para mejorar las relaciones entre niveles de gobierno (Leyva Botero 2011: 213)

En este contexto, el enfoque de las RIGs ayuda a comprender las relaciones que se dan entre el gobierno central y los gobiernos sub-nacionales. Se trata de entender, entre otras cosas, qué nivel de gobierno debería llevar a cabo determinada función, la asignación de recursos, y la distribución de estos entre los distintos niveles sub-nacionales. Este enfoque aporta conocimiento sobre los grados de autonomía, sobre las formas de interrelación de los niveles de gobierno y sobre los resultados que implican estas reformas. Así se puede observar en análisis sobre la descentralización en el caso de Perú y Colombia (Ahmad y García-Escribano 2010; Bello y Espitia 2011; Congreso de la República del Perú 2011; Leyva Botero 2012; Rimisp 2013; Pinilla et al. 2016; Secretaría de Descentralización del Perú 2016).

Es esencial entonces, asumir que para comprender las relaciones intergubernamentales que se dan en el marco de un nuevo proceso de descentralización, (como el que se iniciará en Chile a partir del año 2021) sea necesario conocer el diseño institucional. En especial, las reglas del juego que definirán cómo y a quién se distribuirán las competencias, atribuciones y recursos, bajo las cuales los distintos actores se deberán desenvolver para alcanzar los objetivos del nivel de gobierno donde les corresponde actuar.

Ejemplificando lo anterior, Morata (1991: 154) sostiene que el objeto de las RIGs no consiste tanto en definir los principios y las técnicas en función de los cuales se estructura el sistema de relaciones entre los distintos niveles de gobierno, como en explicar el funcionamiento concreto de dichas relaciones aplicadas a la solución de problemas específicos (políticas y programas). Es relevante detectar los obstáculos institucionales, políticos y administrativos que frenan el desarrollo de la coordinación y la cooperación y determinan el fracaso o la ineficacia de las actuaciones públicas. El marco institucional y, en especial, la distribución de las competencias conforman las reglas del juego e incentivos en el que los distintos actores, dotados de unos determinados recursos jurídicos, políticos, financieros y organizativos, intervienen con arreglo a sus propios objetivos, intereses y estrategias (Morata 1991: 154). De esta manera, la incorporación del enfoque de las RIGs, especialmente a la descentralización, trae necesariamente al centro de la cuestión el tema de las relaciones entre niveles de gobierno. La descentralización, vista así, sirve para desarrollar una explicación más sofis- 
ticada del concepto de autonomía, que tenga en cuenta no sólo el grado de separación, sino también la forma de interrelación de los niveles subnacionales.

Las relaciones intergubernamentales se expresan de diferentes maneras. Jordana (2004) sostiene que, al extenderse progresivamente la descentralización en numerosos países de América Latina, las relaciones intergubernamentales no han experimentado un desarrollo paralelo, con lo que algunos de los problemas típicos de los procesos de descentralización se han agravado. Una de las situaciones típicas aparecidas con bastante frecuencia ha sido lo que el autor denomina la «explotación oportunista» de un nivel de gobierno respecto a otro (Jordana 2004: 128). En otros términos, esta situación consiste en la aparición de comportamientos en un nivel de gobierno que aprovechan las debilidades de los otros niveles para beneficio propio (Jordana 2004: 128). Este problema es bastante frecuente en los temas sociales y en la organización de las trasferencias de recursos entre distintos niveles de gobierno, en los numerosos procesos de descentralización en la región, y se acrecienta en escenarios donde no existen mecanismos formales de cooperación (Jordana 2004: 68), por ejemplo, como lo sucedido en el caso de los Consejos Comunales de Gobierno en Colombia (Leyva Botero 2012: 120).

Por su parte, cuando se produce un escenario donde el nivel nacional, a través de presidencia y de sus ministerios, sigue asumiendo una posición de superioridad frente a las comunidades territoriales, se construye "una relación coordinada", pero claramente desigual en las RIGs. Finalmente, si se da "una relación de tipo paritaria," vendría a configurarse una "relación de cooperación" con aportes y ajustes mutuos de los distintos niveles de gobierno (Rolla 2005: 398).

Todas las dinámicas de relaciones descritas anteriormente presuponen cierta forma institucionalizada de coordinación, no obstante puede darse el caso de que ante la ausencia de relaciones formales, o en escenarios de competencias y atribuciones confusas entre niveles de gobiernos, ni siquiera las relaciones de tipo informal y oportunistas pueden subsanar las problemáticas que se produzcan a raíz de aquello. En estos casos, se puede llegar a un escenario de incoherencias y enfrentamientos continuos, en el que se puede producir un mayor déficit de eficiencia y eficacia de las políticas sociales, conllevando su deslegitimación con respecto a la situación previa que se pretendía resolver (Jordana 2004: 129).

Es decir, se puede dar el caso que ante la ausencia de mecanismos que garanticen una cooperación mínima entre los niveles de gobierno, la descentralización puede terminar siendo un proceso ineficiente y fuente de descrédito para las nuevas autoridades subnacionales. De ahí la relevancia del enfoque de las RIGs para entender el proceso de descentralización no sólo como autonomía, sino como un espacio de relación y cooperación gubernamental que contribuya a mejorar la implementación de políticas públicas a la ciudadanía (Cabrero y Zabaleta 2009: 32). 
Este enfoque ayuda a comprender los problemas frecuentes de los procesos de descentralización en América Latina, como el desbalance entre las competencias y los recursos que tiene la nación (ministerios) en relación con las regiones (departamentos o provincias en otros países) y municipios. Casos como los de Colombia y Perú son ilustrativos para comprender dicha problemática (Bello y Espitia 2011; Congreso de la República del Perú 2011; Leyva Botero 2012; Rimisp 2013; Pinilla et al. 2016; Secretaría de Descentralización del Perú 2016). En estos y otros casos, se confirma que los sistemas de transferencias de América Latina no están diseñados para ofrecer a los gobiernos subnacionales los medios que les permitan adquirir responsabilidades técnicas y administrativas acorde con sus ingresos propios. Las limitaciones más frecuentes de los procesos de descentralización son la falta de claridad sobre las competencias y responsabilidades en la ejecución de políticas públicas, la falta de recursos propios y la ausencia de un mecanismo coordinador de las entidades territoriales (Ahmad y García 2010: 44). En términos generales, la cuestión central es cómo los fenómenos de descentralización ponen a prueba la capacidad de producir mejores políticas públicas en el marco de un proceso de descentralización, así lo reflejan los trabajos sobre Colombia (Leyva Botero 2011: 122), o en países federales como unitarios (Hernández 2006).

En definitiva, el efecto de reformas pro-descentralización será positivo si, por ejemplo, la delegación de responsabilidades están acompañadas por una adecuada capacitación de los niveles subnacionales. Caso contrario, si esto no se cumple, o si la delegación de responsabilidades no está acompañada de la transferencia de los recursos necesarios, afectará la autonomía subnacional (Falleti 2010: 45). En este sentido, las limitaciones más frecuentes que se encuentran en los procesos de descentralización en América Latina son la falta de claridad sobre las competencias y responsabilidades en la ejecución de políticas públicas, la falta de recursos propios y la ausencia de un mecanismo coordinador de las entidades territoriales (Ahmad y García 2010: 44; Congreso República Perú 2011; Molina 2015: 77; Arandia 2016: 414).

De acuerdo a lo anterior será la forma y el contenido de los mecanismos o normas de coordinación que rigen las RIGs lo que garantizará un equilibrio entre los intereses del gobierno central y subnacional. En casos donde los 3 niveles de gobierno son electos popularmente (Chile a partir del año 2021), pero uno de ellos seguirá representando al nivel central, se puede suponer una mayor complejidad de las RIGs, ya que una de las autoridades regionales con atribuciones de gestión estará supeditada jerárquicamente a la superior. Por lo general, este es el caso de los gobiernos intermedios nombrados por las autoridades nacionales, o en otras palabras donde sólo existe descentralización administrativa (Jordana 2002: 12) y no una distribución del poder equitativa en una estructura no-jerárquica (Hernández y Villa 2010). De hecho, las relaciones que se dan en espacios multinivel incluyen la cooperación, la coordinación, el conflicto o la articulación y estas relaciones pueden darse a la vez, dado que la presencia de uno no significa que el otro no aparezca (Wright 1997: 624-625). 
Cuanto más compleja sea esta estructura, más intensas pueden llegar a ser las RIGs o, al menos, los requerimientos de coordinación, aunque también pueden darse importantes problemas de coordinación intergubernamental, siendo este último caso un claro indicador de dificultades de funcionamiento de la descentralización (Hernández y Villa 2010; Zapata 2013).

\section{Reformas políticas a la descentralización en Chile}

Desde el retorno a la democracia, el nivel regional ha sido el que menos reformas políticas pro-descentralización ha sufrido. Desde 1990, cuando se crearon los gobiernos regionales bajo la ley 19.175, se tuvo que esperar más de 20 años para concretar una segunda reforma política sustantiva, que logró que por primera vez se eligieran los consejeros regionales en noviembre del año $2013 .{ }^{2}$ Estas autoridades políticas, cuya función más relevante es fiscalizar y aprobar los recursos regionales correspondientes al Fondo Nacional de Desarrollo Regional (en adelante FNDR), acompañan en la gestión al intendente regional, y hasta antes de esa fecha no eran electas de manera directa por la ciudadanía, sino que eran propuestas por los partidos políticos y elegidos por los concejales de cada comuna.

De acuerdo con Navarrete e Higueras (2014) y siguiendo la teoría secuencial de la descentralización planteada por Falleti (2006), la secuencia del proceso chileno siempre ha tenido un componente donde han predominado los intereses nacionales por sobre los subnacionales y han prevalecido los aspectos administrativos y financieros por sobre los políticos (Navarrete e Higueras 2014: 179). Existiría un origen remoto del proceso, de corte administrativo y fiscal, situado en la dictadura y caracterizado por las reformas impulsadas por CONARA ${ }^{3}$ y la medida fiscal que consideró la creación del FNDR a fines de la década del 70. En ese periodo efectivamente ocurre un cambio sustantivo del proceso de descentralización que históricamente había vivido Chile, específicamente al concebir un modelo de regionalización en un marco de políticas neoliberales. La motivación principal de estas políticas eran razones geopolíticas de integración nacional y reformas que implicaban -o más bien suponían-, que la prestación de bienes y servicios en el espacio local se realizarían de manera más eficiente y eficaz para la ciudadanía (Montecinos 2005: 457).

A partir de la recuperación de la democracia en 1990 y con la promulgación de la ley 19.175 (ley de gobiernos regionales) y la democratización de las autoridades comunales (elección de alcaldes y concejales en 1992), se inicia un

\footnotetext{
Autoridades de nivel intermedio que constituyen el principal cuerpo colegiado regional llamado Consejo Regional, electos a raíz de la modificación a la Constitución Política de Chile del año 2009 (Ley 20.390) cuya labor es normativa, resolutiva (en los ámbitos que define la ley 19.175) y fiscalizadora de la labor de los servicios públicos regionales.

3 Comisión Nacional de Reforma Administrativa, instancia creada por Pinochet y que sugirió la reforma a la regionalización y la reorganización administrativa del país.
} 
nuevo proceso de reformas políticas a la descentralización. En el nivel regional se consolidó la secuencia iniciada en la dictadura de Pinochet. Navarrete e Higueras (2014) argumentan que las razones para que se continúe en esta lógica, se explica por el acuerdo político alcanzado por la elite centralista y particularmente santiaguina, de hacer de la reforma regional un tema que no quite poder a la elite política y al gobierno central, reduciéndolo a un tema relativamente de pocos, que podía ser negociable sin tener mayores impactos y costos ante la ciudadanía (Navarrete e Higueras 2014).

Fue así como a partir del año 1990, en el nivel regional se observa una profundización de la descentralización administrativa, con distintas leyes que transfirieron nuevas atribuciones y facultades a las regiones. Entre las que se puede mencionar los traspasos de potestades administrativas a través de la ley 19.778 del año 2001, donde se establecen atribuciones respecto a la regulación de los planes regionales, metropolitanos, intercomunales y comunales de ordenamiento y desarrollo urbano. Posteriormente, en el año 2005 a través de la ley 20.035 se introducen modificaciones sobre la estructura y funciones de los gobiernos regionales como la de construir, conservar y administrar en las áreas urbanas las obras de pavimentación de aceras y calzadas, función que el Servicio Regional de Vivienda y Urbanismo (SERVIU) tenía dentro de sus atribuciones. Este proceso se fortalece con la creación de dos regiones el año 2007 (Arica-Parinacota y Los Ríos) y la recientemente creada región de Nuble el año 2018.

Por su parte, las reformas políticas a escala regional comienzan a tomar forma con modificaciones a la constitución política de Chile. Primero, el año 2009 por medio de la ley 20.390 permitió la elección directa y universal de los consejeros regionales, lo cual se concretó recién el año 2013. La segunda, es la reciente reforma constitucional contenida en la ley 20.990 que permitirá la elección de gobernadores regionales a partir de octubre del año 20204 (Biblioteca del Congreso Nacional 2017), la que fue pospuesta finalmente para abril del año 2021.

En resumen, las principales reformas a la descentralización chilena en la escala regional, se pueden clasificar en 3 periodos.

El primero va desde 1974 hasta la recuperación de la democracia. En él se instaló el actual modelo de desconcentración regional (primeras oficinas ministeriales y servicios públicos en regiones), bajo la tutela política y administrativa de un intendente regional, quien tenía como misión la unificación de los espacios de intervención de los distintos servicios públicos a nivel regional (Navarrete e Higueras 2014). 
Un segundo periodo se puede observar desde 1990 a 2013, en este se consolida un modelo con predominancia de la desconcentración basada en la organización diseñada en 1974. Esta estructura se complementa con la creación del gobierno regional por la ley 19.175 en 1992, compuesto por el consejo regional y su ejecutivo (intendente regional), cuya principal función es asignar recursos (FNDR) en función de la demanda promovida por los municipios y servicios públicos.

Un tercer periodo se puede distinguir desde el año 2013 (elección de los consejeros regionales) y que se acrecentará a partir del año 2021 con la elección de gobernador regional. Lo complejo de este nuevo diseño es que esta nueva autoridad, no reemplazará integralmente en sus funciones al intendente regional, ya que paralelo a la autoridad electa, la nueva ley (20.990 del año 2017) contempló la existencia de una autoridad designada que se llamará delegado presidencial regional, el que tendrá atribuciones de coordinación política sobre los servicios públicos desconcentrados en la región (leyes 21.073 y 21.074).

Esta situación provocará una dinámica de relaciones intergubernamentales inédita en América Latina y en Chile, lo que alterará el funcionamiento del actual diseño descentralizado y las relaciones intergubernamentales.

\section{Funcionamiento del actual modelo de descentralización y de relaciones intergubernamentales.}

El actual diseño institucional establece que las autoridades políticas de nivel regional son designadas, es decir, el Intendente Regional siempre ha sido designado por el ejecutivo nacional, en particular por la presidencia de la república. A su vez, esta autoridad a partir del año 1992, en conjunto con los ministros puede designar a los Secretarios Regionales Ministeriales (SEREMIS). Estos son los órganos desconcentrados ministeriales y los servicios públicos nacionales con presencia en regiones, y mantienen la coordinación política bajo la autoridad administrativa del intendente regional, principal responsable de la articulación política de los servicios región/país.

De acuerdo con lo señalado por Navarrete e Higueras (2014) el modelo de descentralización política se encuentra caracterizado por el alto nivel de nacionalización partidaria y baja articulación regional. En la práctica política, esto trae como principal consecuencia que quienes proponen, debaten y aprueban la legislación asociada a temas de descentralización, son quienes se benefician de mantener las cosas tal como están. Por esta razón, los intereses nacionales se han impuesto por sobre los intereses subnacionales, ya que los principales incentivos políticos se hallan en los niveles nacionales de gobierno (Navarrete e Higueras 2014: 192-193).

Como consecuencia, la actividad gubernamental regional genera una dependencia muy directa a las autoridades centrales, en desmedro de las decisiones 
de alcaldes, consejeros regionales e inclusive de las decisiones o voluntad política del propio intendente regional. Estos últimos tienen como misión articular políticas públicas regionales, pero en función de los intereses nacionales y no necesariamente territoriales, dado que si un intendente regional aspira a representar fielmente las demandas de las regiones que representan, corre el riesgo de ser desvinculado de su cargo ya sea por presiones de parlamentarios al ejecutivo nacional, o simplemente por decisión propia del presidente de la república. Aún con esta limitación política y falta de legitimidad democrática ante la ciudadanía, en regiones es el intendente regional quien tiene la misión de coordinar los servicios públicos regionales, promover la coordinación con ministerios sectoriales y trabajar coordinadamente con alcaldes.

\section{Cambios politicos al modelo de descentralización y relaciones intergubernamentales.}

Las principales modificaciones a la descentralización política (leyes 21.074 y $20.990)^{5}$ contienen la eliminación de la figura del intendente regional y las competencias y funciones de las nuevas autoridades regionales. Como consecuencia, separa la línea de gobierno interior (orden y seguridad pública) de la de administración regional, que hasta antes de estas reformas recaían única e íntegramente en el intendente regional. Como reemplazo de la función de gobierno interior, se crea la figura de delegado presidencial regional, actor político de exclusiva confianza del presidente de la república. Como reemplazo de la función de administración regional, se crea la figura del gobernador regional, actor político electo por sufragio universal, quien cumplirá la función de ejecutivo del gobierno regional y presidente del consejo regional (Biblioteca del Congreso Nacional 2017; 2018).

Con este diseño se termina con la doble dependencia que implicaba representar simultáneamente los intereses regionales y los del ejecutivo nacional en la región. A cambio se crean dos nuevas figuras políticas que convivirán en una misma región, ambas compartiendo ámbitos de acción con similares atribuciones y competencias, tal como se demuestra a continuación.

\section{a. Competencias del Delegado Presidencial Regional}

La ley 20.990 establece que el delegado presidencial regional será una autoridad designada por el presidente de la república y tendrá como función dirigir las tareas de gobierno interior. Anteriormente estas funciones le correspondían al intendente regional, como por ejemplo, velar por el orden público y resguar-

La reforma constitucional del 2017 ley 20.990 dispone la elección popular del órgano ejecutivo del gobierno regional y la creación de la nueva autoridad regional designada llamada delegado presidencial regional. La ley 21.074 (fortalecimiento de la regionalización del país) establece facultades, competencias y nuevas funciones del gobierno regional, lo cual incluye modificaciones a la ley 19.175 de gobierno y administración regional. 
do de las personas y bienes, requerir el auxilio de la fuerza pública, aplicar las disposiciones de la ley de extranjería, adoptar todas las medidas necesarias para prevenir y enfrentar situaciones de emergencia o catástrofe.

De vital importancia es la competencia y función de coordinación de servicios públicos que esta nueva legislación le asigna. La ley señala que podrá ejercer coordinación y supervigilancia de los servicios públicos desconcentrados, es decir, de los servicios públicos presentes en la región y de los secretarios regionales ministeriales (SEREMIS), lo que antes hacía el intendente regional.

Para comprender la importancia de esta función, es necesario señalar que las secretarías regionales ministeriales y los servicios públicos desconcentrados, representan en promedio entre el $70 \%$ y $80 \%$ de la inversión pública efectiva que se ejecuta en una región. Otra de las funciones y competencias relevantes que cumplirá el delegado residencial serán: proponer al presidente de la república la designación de los SEREMIS; hacer presente a las autoridades regionales y nacionales con oportunidad las necesidades de la región; y supervisar los programas y proyectos de desarrollo que los servicios públicos.

\section{b. Competencias de Gobernador Regional. ${ }^{6}$}

A partir del año 2021 el nuevo gobierno regional lo constituirá el gobernador y el consejo regional. El gobernador ejercerá las funciones de presidente del consejo regional y ejecutivo del gobierno regional. Adicionalmente deberá coordinar y fiscalizar a los servicios públicos que dependan o se relacionen con el gobierno regional, así como formular políticas de desarrollo de la región, considerando las políticas y planes comunales respectivos.

En esta primera función se puede observar una potencial tensión con el delegado presidencial regional, dado que, a diferencia de éste, el gobernador regional no tendrá autoridad administrativa ni política sobre las secretarías regionales ministeriales ni sobre los servicios públicos que dependan directamente del gobierno regional. Por ejemplo, la secretaría regional ministerial de obras públicas invierte en algunas regiones (como por ejemplo la Región de Los Ríos) el doble del presupuesto del gobierno regional. Esta autoridad que no dependerá del gobernador regional sólo podrá coordinarse con la autoridad legítimamente electa pero no tendrá autoridad de mando sobre ella. El mando administrativo lo tendrá la autoridad regional designada. Antes de esta reforma esa función recaía única e íntegramente en el intendente regional.

Otra de las funciones será someter al consejo regional el proyecto de presupuesto y la distribución de los recursos del o los programas de inversión del gobierno regional, así como proponer la celebración de convenios de progra-

Esta nueva autoridad se elegirá con el $40 \%$ de los votos de lo contrario se irá a una segunda vuelta, durará 4 años en su cargo y podrá ser reelegido sólo por un periodo consecutivo. 
mación con ministerios o servicios públicos. ${ }^{7}$ La incidencia sobre el presupuesto de los servicios públicos desconcentrados presentes en la región (seremis o direcciones regionales de servicios) será indirecta. El principal instrumento financiero que será de administración directa para el gobernador regional, será el fondo nacional de desarrollo regional. Ese fondo representa entre un 20 a $30 \%$ de la inversión pública efectiva en una región (dependiendo del tamaño de la región). Como consecuencia, el delegado presidencial regional será un importante jugador de veto en la discusión presupuestaria de las regiones, especialmente las de tipo sectorial.

Las competencias y funciones exclusivas del gobernador regional serán la formulación del plan regional de ordenamiento territorial, los planes reguladores metropolitanos e intercomunales, comunales y seccionales y los planos de detalle de planes reguladores intercomunales. A su vez será también proponer al consejo regional los proyectos de reglamentos regionales que regulen materias propias de la competencia del gobierno regional.

\section{c. Competencias de secretarios regionales ministeriales}

Antes de esta reforma, los secretarios regionales ministeriales tenían dependencia del ministerio respectivo y del intendente regional, siendo esta última autoridad quien ejercía la coordinación política en cada una de las regiones. A partir del año 2021 dependerán del ministerio respectivo y del delegado presidencial regional en regiones, no teniendo relación jerárquica y administrativa con el gobernador regional. Las funciones de estas autoridades será presentar al ministerio respectivo las prioridades regionales, para efectos de la formulación de las políticas nacionales, considerando la diversidad territorial y cultural de la región, informar a los ministros respectivos sobre las políticas, programas y proyectos de los gobiernos regionales y su coherencia con las políticas nacionales.

En materia de inversión pública sectorial, tendrán como función preparar el anteproyecto de presupuesto regional en la esfera de su competencia, en coordinación con el ministerio respectivo. Informar permanentemente al gobierno regional del cumplimiento del programa de trabajo del respectivo sector y realizar tareas de coordinación o fiscalización sobre todos los organismos de la administración del Estado que dependan o se relacionen con el presidente de la república y que integren su respectivo sector. En este ámbito deberá velar de

Otra de las funciones contempladas en la ley para el Gobernador Regional son las siguientes: Proponer al consejo regional el anteproyecto regional de inversiones. Representar judicial y extrajudicialmente al gobierno regional, pudiendo ejecutar los actos y celebrar los contratos de su competencia o los que le encomiende el consejo. Nombrar y remover a los funcionarios que la ley determine como de su confianza. Velar por el cumplimiento de las normas sobre probidad administrativa. Ejercer la administración de los bienes y recursos propios del gobierno regional. Administrar, en los casos que determine la ley, los bienes nacionales de uso público. Dictar las resoluciones e instrucciones que estime necesarias para el ejercicio de sus atribuciones 
forma especial por el cumplimiento de los convenios de programación y mandato que convengan entre el gobierno regional y los ministerios en la región.

\section{Dinámicas de relaciones intergubernamentales a escala regional.}

En la actualidad, las autoridades políticas de nivel regional (intendente y SEREMIS), se relacionan hacia arriba con los ministros y presidentes, y hacia abajo con los alcaldes de las municipalidades, y en el nivel regional la coordinación política la encabeza el intendente regional. Las relaciones intergubernamentales se dan en esos niveles y direcciones, y entre el nivel regional y nacional adquieren características de cooperación, coordinación, sin la presencia de conflictos sustantivos o bloqueos, por la razón de que todas estas autoridades son designadas.

Los conflictos en la coordinación política aparecen entre autoridades regionales y municipales (éstas últimas electas), sobre todo cuando son de distinta filiación política. El bloqueo de políticas públicas es prácticamente inexistente dada la naturaleza del centralismo, y de los escasos recursos económicos que manejan las autoridades municipales, quienes son las que podrían realizar bloqueo a políticas públicas nacionales o regionales. ${ }^{8}$

Aún no es posible señalar con exactitud cuál será la intensidad de estas relaciones a partir del año 2021, pero sí se puede adelantar la naturaleza y la dirección que tendrán. En primer término, habrá más jugadores con posibilidad de veto y se agregará un actor político regional con legitimidad democrática y ciudadana, a diferencia de lo que sucede hoy donde todos los actores regionales son designados por el poder central.

Esto hará complejo el entramado político, pero sobre todo el entramado de la gestión regional, porque el delegado presidencial regional no será una figura "administrativa". Dada las competencias que la ley le confiere, pueden terminar siendo determinantes para prever un comportamiento más político que protocolar en su desempeño. Las RIGs no serán sólo hacia arriba o hacia abajo, sino también de manera horizontal al interior de la región entre autoridades con rango y competencias similares, pudiendo darse un esquema de relaciones intergubernamentales que va desde cooperación plena entre todos los actores y niveles de gobierno involucrados en la gestión territorial, hasta escenarios de conflicto alto entre autoridades electas y designadas.

A continuación, se presentan cuatro posibles escenarios de relaciones intergubernamentales que podrían darse en el nuevo contexto regional, donde convivirán autoridades electas y designadas.

En las municipalidades que podrían darse relaciones más conflictivas, son aquellas de mayor tamaño y capitales regionales (esto último podría darse fundamentalmente con municipalidades de oposición al gobierno central y como consecuencia a los actuales gobiernos regionales). 


\section{Escenario 1: Colaboración plena}

En el cuadro 1 se ve reflejado el tipo ideal de relación intergubernamental que se espera, es decir, todos los niveles de gobierno colaborando y cooperando para sacar adelante los objetivos de la gestión regional. En la práctica se podría esperar este tipo de relaciones cuando la adscripción política de la coalición de gobierno coincide con la coalición del gobernador regional y con los alcaldes a nivel de municipalidades. Como la coalición o partido gobernante, tiene el derecho de designar SEREMIS y delegado presidencial regional, se asume que a nivel regional estas autoridades no serán de una coalición opositora y no serían fuente de producción de conflictos.

Cuadro 1. Escenario de colaboración plena

\begin{tabular}{ccccc}
\hline $\begin{array}{c}\text { Nivel de Gobierno/ } \\
\text { Tipo de relaciones }\end{array}$ & $\begin{array}{c}\text { Ministerios y } \\
\text { Presidencia }\end{array}$ & $\begin{array}{c}\text { Gobernador } \\
\text { Regional }\end{array}$ & $\begin{array}{c}\text { Delegado Presidencial } \\
\text { Regional y SEREMIS }\end{array}$ & Municipios \\
\hline $\begin{array}{c}\text { Cooperación y } \\
\text { Coordinación }\end{array}$ & $\mathrm{X}$ & $\mathrm{X}$ & $\mathrm{X}$ & $\mathrm{X}$ \\
Conflicto o Bloqueo & - & - & - & - \\
\hline
\end{tabular}

A nivel regional, se presupone entonces que no debieran existir inconvenientes entre gobernador y delegado presidencial para colaborar, por ejemplo, en la coordinación de los servicios públicos regionales que no dependen jerárquicamente del gobernador, pero sí lo hacen del delegado presidencial.

No obstante aquello, siempre pueden darse situaciones dentro de este escenario, donde habrá algún delegado presidencial regional y/o secretario regional ministerial de la misma coalición política, que quisiera destacar en su ámbito de acción para competir por el escaño del gobernador regional, asumiendo niveles de protagonismo político, que entren en conflicto con la nueva autoridad electa. A su vez, de parte del gobernador regional existirá el incentivo de liderar la gestión en la región, haciendo valer su peso electoral para suplir la ausencia de potestad administrativa sobre servicios regionales que no dependen de su autoridad para colaborar en la consecución de los objetivos de desarrollo y que cuentan con los recursos para ello.

\section{Escenario 2: Colaboración alta y conflicto leve}

En el cuadro 2 se puede ver reflejado un probable escenario, en donde exista colaboración y cooperación entre gobierno central, delegado regional, SEREMIS y gobernador regional, pero se produzcan conflictos producto de la falta de cooperación con una municipalidad de distinta coalición política que entra en tensión con la coalición gobernante. La motivación puede ser simbólica, dado 
que representa un interés genuino de la coalición predominante para hacerse de la municipalidad, o puede existir un interés electoral específico para derrotar al alcalde de dicha municipalidad.

Este escenario se define como cooperación con conflicto leve, porque la envergadura que representa la inversión pública de los municipios en relación a la inversión pública efectiva que suman el nivel regional y nacional en una comuna no es significativo. Como consecuencia, el impacto que puede provocar en la ciudadanía el hecho de que un alcalde entre en conflicto con el nivel nacional y regional es menor. Aunque se den situaciones de conflicto, la inversión sectorial y regional se va a concretar igualmente producto de los instrumentos de planificación sectoriales, que muchas veces son de largo plazo y concentrado en obras de continuidad..$^{9}$ Ahora bien, si esta situación se llega a provocar en aquellos municipios que cuentan con mayor notoriedad pública y capacidad financiera, se podrían producir situaciones de conflicto mayormente notorios, sobre todo en lo mediático. Las municipalidades que cuentan con estas características y donde podrían provocarse dichos escenarios no son más de 20 en el país de un total de 345 .

Cuadro 2. Escenario de colaboración alta y conflicto leve

\begin{tabular}{ccccc}
\hline $\begin{array}{c}\text { Nivel de Gobierno/ } \\
\text { Tipo de relaciones }\end{array}$ & $\begin{array}{c}\text { Ministerios y } \\
\text { Presidencia }\end{array}$ & $\begin{array}{c}\text { Gobernador } \\
\text { Regional }\end{array}$ & $\begin{array}{c}\text { Delegado Presidencial } \\
\text { Regional y seremis }\end{array}$ & Municipios \\
\hline $\begin{array}{c}\text { Cooperación y } \\
\text { colaboración }\end{array}$ & $\mathrm{X}$ & $\mathrm{X}$ & $\mathrm{X}$ & - \\
Conflicto o Bloqueo & - & - & - & $\mathrm{X}$ \\
\hline
\end{tabular}

Situaciones como las señaladas y que puedan repercutir en la ciudadanía, podrían provocarse en aquellas municipalidades que son simbólicas en términos políticos y que son vistas por las coaliciones como trofeos electorales, llámese capitales regionales y con mayor capacidad de inversión como, por ejemplo, Concepción, Valparaíso, Puerto Montt, Santiago, Temuco, Valdivia, Las Condes, Vitacura, entre otras. Pero la posibilidad de bloqueos como sucede en países como Colombia o Perú, donde la capacidad financiera subnacional es mayor que en Chile, tiene muy pocas posibilidades de suceder, dada la presencia de burocracia en todo el territorio nacional y la poca capacidad financiera de los gobiernos subnacionales. En Chile, la burocracia se despliega en todo el 
territorio nacional independientemente de que exista oposición local o regional al nivel nacional.

\section{Escenario 3: Cooperación y conflicto medio}

Este escenario describe un contexto donde el gobernador regional, entra en tensión con el nivel nacional y las autoridades regionales designadas, situación ante la cual eventualmente se suman municipalidades, que por afinidad política con el nivel nacional o por actuación estratégica (competencia electoral por el escaño del gobernador) entran en conflicto con esta autoridad. Por ejemplo, si un alcalde de capital regional o de otra comuna, aspira a ocupar el cargo de gobernador regional, y hace alianza con las autoridades regionales designadas para mostrar una gestión que aísle a esta autoridad, se producirían altas probabilidades de no tener coordinación y entrar en escaladas de conflictos políticos regionales.

Cuadro 3. Escenario de cooperación y conflicto medio

\begin{tabular}{ccccc}
\hline $\begin{array}{c}\text { Nivel de Gobierno/ } \\
\text { Tipo de relaciones }\end{array}$ & $\begin{array}{c}\text { Ministerios y } \\
\text { Presidencia }\end{array}$ & $\begin{array}{c}\text { Gobernador } \\
\text { Regional }\end{array}$ & $\begin{array}{c}\text { Delegado Presidencial } \\
\text { Regional y seremis }\end{array}$ & Municipios \\
\hline $\begin{array}{c}\text { Cooperación y } \\
\text { colaboración }\end{array}$ & $\mathrm{X}$ & - & $\mathrm{X}$ & $\mathrm{X}$ \\
Conflicto o Bloqueo & - & $\mathrm{X}$ & - & - \\
\hline
\end{tabular}

A diferencia del escenario anterior, se considera que es de mayor complejidad porque el conflicto no se sitúa en una comuna específica, sino que se podría expandir en la región, y el volumen de inversión pública involucrado es mucho más alto. Los recursos regionales representan entre un 10\% y 30\% de la inversión pública efectiva en un territorio, esta variación depende del tamaño de la región.

Este escenario se prevé altamente pernicioso dado que afectaría al nivel de gobierno y a la legitimidad de la nueva autoridad política que forma parte nuclear del proceso de descentralización impulsado en Chile. De darse este escenario se corre el riesgo de que la ciudadanía perciba la ineficacia de elegir autoridades regionales y se cuestione la legitimidad de su existencia, contribuyendo con ello a un deterioro temprano de la legitimidad democrática de la nueva autoridad regional.

\section{Escenario 4: Escenario de cooperación baja y conflicto alto}

Este es el escenario menos deseado para la gestión regional, dado que implicaría dinámicas de poca colaboración y coordinación entre las autoridades nacionales y regionales designadas, con las autoridades regionales y comunales 
democráticamente electas. El hecho de pertenecer a coaliciones políticas distintas o una competencia por los escaños de representación popular, pueden provocar escenarios de conflicto de no imponerse la necesidad de la colaboración y la cooperación para alcanzar los objetivos de desarrollo para la comunidad.

Se califica de alto ya que se pueden ver retrasadas obras de carácter estratégico o detenidos los principales instrumentos de colaboración nación-región que hoy existen en la institucionalidad pública chilena. Estos instrumentos son conocidos como los convenios de programación ${ }^{10}$ e involucran grandes cantidades de dinero de la región y de los ministerios involucrados.

\section{Cuadro 4. Escenario de cooperación baja y conflicto alto}

\begin{tabular}{ccccc}
\hline $\begin{array}{c}\text { Nivel de Gobierno/ } \\
\text { Tipo de relaciones }\end{array}$ & $\begin{array}{c}\text { Ministerios y } \\
\text { Presidencia }\end{array}$ & $\begin{array}{c}\text { Gobernador } \\
\text { Regional }\end{array}$ & $\begin{array}{c}\text { Delegado Presidencial } \\
\text { Regional y seremis }\end{array}$ & Municipios \\
\hline $\begin{array}{c}\text { Cooperación y } \\
\text { colaboración }\end{array}$ & $\mathrm{X}$ & - & $\mathrm{X}$ & - \\
Conflicto o Bloqueo & - & $\mathrm{X}$ & - & $\mathrm{X}$ \\
\hline
\end{tabular}

Este es el escenario que mantuvo a los legisladores en duda permanente para aprobar la ley de elección de gobernadores regionales, y que aún es usado como argumento para retrasar las elecciones de gobernador regional porque será considerado una fuente inagotable de generación de conflictos. ${ }^{11}$ Revela las tensiones que necesariamente existirán entre conciliar la legítima autonomía asociada a la descentralización, con la necesaria unidad administrativa que debe garantizar el Estado.

Los vacíos que puede provocar la implementación de este nuevo diseño institucional descentralizado podrían terminar siendo aprovechados por caudillos locales o regionales, o en procesos de recentralización populistas (como lo fue el caso de los Consejos Comunales de Presidente Uribe en Colombia). ${ }^{12}$

Al igual que el escenario anterior, esta dinámica puede terminar siendo perniciosa para la legitimidad de la nueva autoridad política y mucho más intensa en lo que se refiere a conflictos políticos (por la sumatoria de alcaldes como aliados al gobernador regional en contra del gobierno nacional y las autorida-

10 Los convenios de programación son instrumentos de colaboración que involucran recursos de nivel ministerial y regional. Se usan habitualmente en áreas como Salud, Obras Públicas, Agricultura entre otras. En general la distribución porcentual de los recursos son 60\% ministerios y 30\% región. El horizonte temporal suele ser de 3 a 6 años. En la actualidad estos instrumentos suelen no presentar grandes complejidades en su Operacionalización dado que tanto Intendente como Seremis y Ministros son de la misma coalición política.

11 Medios de prensa se han hecho eco de esta tesis, como por ejemplo, la aparecida en el Mercurio el día 25 de Enero de 2019, accesible digitalmente en http://www.economiaynegocios.cl/noticias/noticias.asp?id=541265

12 Leyva Botero (2012) 
des regionales designadas). Fuente generadora de motivos para re-centralizar o no transferir competencias desde el nivel central a las regiones para profundizar el proceso de descentralización política.

\section{Síntesis y propuesta}

La situación más compleja en términos de relaciones intergubernamentales, serán los potenciales problemas de coordinación política que existirán entre los niveles de gobierno nacional y subnacional, en específico, entre las dos nuevas autoridades regionales.

Ante este contexto, los escenarios descritos anteriormente cuentan con una alta probabilidad de que existan debido a que las reformas y la nueva legislación no contempló una instancia de coordinación política regional, que goce de autoridad política y administrativa, sobre los servicios públicos descentralizados y desconcentrados en la región.

En concreto, cabe preguntarse ¿cómo resolver esta situación? La actual legislación, no contempla una instancia formal de coordinación para estos efectos. No obstante, aquello, la principal institución donde debiera recaer esta responsabilidad es en el consejo regional. Este es el órgano legítimo y representativo de la región, en él se refleja la diversidad política y territorial y será presidido por el gobernador regional. En esta instancia debiera recaer, al menos en una primera etapa del proceso de descentralización, la responsabilidad de garantizar una mínima coordinación política de los servicios públicos, descentralizados y desconcentrados, presentes en cada una de las regiones.

¿Cómo hacerlo?, amparado en la ley 19.175 de gobiernos regionales se puede implementar a través de la creación de una "Comisión de Coordinación Política Regional" que debiera estar integrada de manera permanente por el gobernador regional, el delegado presidencial regional y los consejeros regionales. Esta instancia se puede hacer sin necesidad de modificar la legislación recientemente aprobada, dado que la ley 19.175 de gobiernos regionales, en su artículo 36, inciso "a", faculta al consejo regional para "aprobar el reglamento que regula su funcionamiento en el que se podrá contemplar la existencia de diversas comisiones de trabajo". Para concretar esta idea, basta con la voluntad política de los consejos regionales existentes en el país para crear esta comisión de coordinación política regional y anticiparse a este tipo de situaciones.

La utilidad de una comisión de coordinación política regional se fundamenta en evitar o minimizar la ocurrencia de problemas de coordinación a escala regional, y reducir el impacto negativo que puede generar ante la ciudadanía el hecho de debutar con nuevas autoridades políticas, que presenten graves problemas de coordinación a escala territorial. Segundo, con ello también se puede contribuir a reducir la posibilidad de que la descentralización política se transforme en un proceso que traiga como consecuencia "hacer las cosas peor 
que antes", y que produzca la sensación de des legitimidad temprana en la ciudadanía de esta nueva autoridad regional.

\section{CONCLUSIONES}

El proceso chileno de descentralización se caracteriza por una fuerte presencia del Estado y sus servicios en todo el territorio nacional, proceso top down que ha sido promovido por fuerzas políticas nacionales pro-descentralización, lo cual ha hecho que en sus avances predomine la agenda del gobierno central. Es un diseño eficaz en lo que se refiere a cubrir con prestación de servicios del Estado todo el territorio nacional, pero con escasa legitimidad democrática e inestabilidad en la conducción de la planificación a escala regional, dado que los intendentes regionales permanecen en promedio 18 meses en el cargo.

Este diseño explica lo tardío del proceso de democratización de autoridades regionales y la conservadora reforma política que se aprobó para avanzar en materia de descentralización política. La cual incluye dos autoridades, una designada y otra democrática, compartiendo ámbitos de acción, funciones y competencias en la misma unidad administrativa. Como consecuencia, es evidente que la nueva legislación promueve incentivos para que en vez de tener solamente una autoridad regional coordinando servicios públicos y haciendo "gestión regional", existan dos autoridades, ya sea colaborando, compitiendo o entrando en conflicto al interior de una misma región.

Las reformas aprobadas carecen de una instancia que garantice la debida coordinación política que requerirá la implementación de este nuevo diseño. Parece ser que mientras la descentralización política se entendió como autonomía y un asunto de reglas formales, se descuidó el sostenimiento práctico de la coordinación y relación de niveles de gobierno que esto conlleva, dejando su ejecución sujeta a una cuestión sumamente informal y a actores y prácticas discrecionales. De esta manera, la discrecionalidad, con lo aleatorio que esto significa, puede transformarse no sólo en el móvil de las nuevas relaciones intergubernamentales, sino que peor aún, puede llegar a ser la expresión misma de la tan anhelada descentralización política en Chile.

La ausencia de normas claras de coordinación puede terminar produciendo vacíos institucionales que serán aprovechados por políticos oportunistas que buscan capitalizar esta debilidad para afianzar una carrera electoral y de intermediación entre actores subnacionales y nacionales. Frente a la debilidad de los mecanismos de coordinación, o a la subordinación de las autoridades subnacionales democráticamente electas, contradictoriamente puede aumentar el poder y la visibilidad del nivel central expresado en regiones, provocándose en la práctica un contrasentido de la descentralización.

La propuesta de instalación de una "comisión de coordinación política regional" en cada una de las regiones del país, amparada en la ley 19175, es más que 
una medida que aspira a suplir la debilitada y confusa reforma a la descentralización. Se plantea como el tránsito de un modelo de descentralización, en el que el énfasis inicial se hizo en la democratización de las autoridades regionales y la distribución (confusa) de competencias a todos los niveles, a un modelo de descentralización e interdependencia, bajo un sistema de relaciones intergubernamentales con claras competencias y que fortalecen la coordinación y cooperación de los distintos niveles subnacionales.

\section{BIBLIOGRAFÍA}

Ahmad, Ehtisham y Mercedes García-Escribano. 2010. "Economía política de la descentralización y gobernabilidad." En La Alternativa Local. Descentralización y Desarrollo Económico, editado por Rafael De la Cruz, Carlos Pineda y Caroline Pöschl. Banco Interamericano de Desarrollo, 203-220.

Arandia, Iván. 2016. Descentralización y relaciones intergubernamentales en Bolivia (1994-2006). Memoria para optar al grado de Doctor en Gobierno y Administración Pública. Madrid: Instituto Ortega y Gasset.

Bello, Ricardo y Jorge Espitia. 2011. “Distribución Regional de las Transferencias Intergubernamentales en Colombia 1994-2009". Documentos y Aportes en Administración Pública y Gestión Estatal 11(16): 7-50.

Biblioteca del Congreso Nacional. 2017. “Ley 20.990 Dispone la Elección del Órgano Ejecutivo del Gobierno Regional", promulgada por el Gobierno de Chile el 5 de enero de 2017.

Biblioteca del Congreso Nacional. 2018. "Ley 21.074 Fortalecimiento de la Regionalización del País", promulgada por el Gobierno de Chile el 2 de febrero de 2018.

Cabrero, Enrique y Dionisio Zabaleta. 2009. “¿Cómo construir una mística intergubernamental en la política social? Análisis de cuatro experiencias latinoamericanas." Revista del CLAD Reforma y Democracia (43): 27-62.

Congreso de la República del Perú. 2011. Evaluación del proceso de Descentralización. Informe anual periodo legislativo 2010-2011. Primera Edición. Lima: Comisión de Descentralización, Regionalización, Gobiernos Locales y Modernización de la Gestión del Estado.

Falleti, Tulia. 2006. "Una teoría secuencial de la descentralización: Argentina y Colombia en perspectiva comparada." Revista de Ciencias Sociales 46 (183): 317-351.

Falleti, Tulia. 2010. Decentralization and Subnational Politics in Latin America. New York: Cambridge University Press.

Hernández, Ana María. 2006. "Relaciones intergubernamentales." Revista Espacios Públicos 9(18): 36-53.

Hernández, David y Sughei Villa Sánchez. 2010. “El modelo de relaciones intergubernamentales en la Descentralización en México." Revista Si Somos Americanos Revista de Estudios Transfronterizos 10(1): 103-129.

Jordana, Jacint. 2002. "Relaciones intergubernamentales y descentralización en América Latina Casos de Argentina y Bolivia." Documento de trabajo, Proyecto Conjunto Indes-Unión Europea. Departamento de Integración y Programas Regionales Instituto Interamericano para el Desarrollo Social. Banco Interamericano de Desarrollo. Serie de Documentos de Trabajo I-38UE.

Jordana, Jacint. 2004. “Las relaciones intergubernamentales en la descentralización de las políticas sociales." En Descentralización y Políticas Sociales en América Latina, editado por Ricard Gomá y Jacint Jordana. Barcelona: Fundación CIDOB, 1-348.

Leyva Botero, Santiago. 2011. "Hacia un nuevo debate sobre la descentralización en Colombia: el análisis intergubernamental desde una lectura institucional." Revista CS (8): 211-243. 
Leyva Botero, Santiago. 2012. "Las relaciones Intergubernamentales en Colombia (20022010): Un análisis de los Concejos Comunales de Gobierno." Revista análisis político (76):119-138.

Molina, Isabel. 2015. Las relaciones intergubernamentales en la descentralización de Ecuador. Memoria para optar al grado de doctor en Gobierno y Administración Pública. Madrid: Instituto Ortega y Gasset.

Montecinos, Egon. 2005. “Antecedentes sobre la relación histórica centralismo y descentralización en Chile." Revista Venezolana de Gerencia 10(31): 443 - 462.

Morata, Francesc. 1991. "Políticas públicas y relaciones intergubernamentales." Revista de Documentación Administrativa 224-225:153-166.

Navarrete, Bernardo y Víctor Higueras. 2014. “Chile desde la Teoría secuencial de la descentralización, 1990-2010." Convergencia. Revista de Ciencias Sociales 21(66): 179-202.

Pinilla-Rodríguez, Diego, Juan Jiménez y Roberto Montero. 2016. “Descentralización fiscal y crecimiento económico. La experiencia reciente de América Latina." Revista Desarrollo y Sociedad 77(1): 11-52.

Rimisp, Centro Latinoamericano para el Desarrollo Rural. 2013. Balance preparado por el grupo propuesta ciudadana para la ANGR. En Proyecto Gobernanza Subnacional para el Desarrollo Territorial en Los Andes. Lima: Rimisp.

Rolla, Giancarlo. 2005. "Las relaciones entre niveles institucionales en los Estados Federales y Regionales: Autonomía, Unidad e Integración." Anuario Iberoamericano de Justicia Constitucional Documento de Trabajo (9) 379-400.

Secretaría de Descentralización del Perú. 2016. Informe Anual sobre el Estado del proceso de Descentralización a Enero de 2016. Lima: Programa ProDescentralización de USAID.

Wright, Deli. 1997. Para entender las Relaciones Intergubernamentales. México: Fondo de Cultura Económica.

Zapata, Olga. 2013. "El estudio de las relaciones entre niveles del gobierno desde las relaciones intergubernamentales y la gobernanza multinivel." Revista Estudios de Derecho 70(156): 323-345.

Recibido: 29 de enero de 2019

Aceptado: 10 de noviembre de 2019

Egon Elier Montecinos es trabajador social, Magister en Ciencias Sociales y Doctor en Ciencias Sociales mención en Ciencia Política. Es Académico de la Universidad Austral de Chile, donde es Director del Centro de Estudios Regionales (Cer Uach); y del Instituto de Administración de la Facultad de Ciencias Económicas y Administrativas de la misma casa de estudios. Ha ejercido docencia de pre y posgrado en diversas universidades chilenas y extranjeras. Su línea de investigación y publicaciones es en descentralización, democracia participativa en gobiernos subnacionales. Correo electrónico: egon.montecinos@uach.cl 
